
Qiujuan ZHANG

\title{
Review of materials used in laser-aided additive manufacturing processes to produce metallic products
}

(C) The Author(s) 2019. This article is published with open access at link.springer.com and journal.hep.com.cn

\begin{abstract}
Rapid prototyping (RP) or layered manufacturing (LM) technologies have been extensively used to manufacture prototypes composed mainly of plastics, polymers, paper, and wax due to the short product development time and low costs of these technologies. However, such technologies, with the exception of selective laser melting and sintering, are not used to fabricate metallic products because of the resulting poor life, short cycle, poor surface finish, and low structural integrity of the fabricated parts. The properties endowed by these parts do not match those of functional parts. Therefore, extensive research has been conducted to develop new additive manufacturing (AM) technologies by extending existing RP technologies. Several AM technologies have been developed for the fabrication of metallic objects. These technologies utilize materials, such as Ni-, Al-, and Ti-based alloys and stainless steel powders, to fabricate high-quality functional components. The present work reviews the type of materials used in laserbased AM processes for the manufacture of metallic products. The advantages and disadvantages of processes and different materials are summarized, and future research directions are discussed in the final section. This review
\end{abstract}

Received April 10, 2018; accepted July 8, 2018

Xiaodong NIU, Akhil GARG $(\bowtie)$, Xiongbin PENG

Intelligent Manufacturing Key Laboratory of Ministry of Education, Shantou University, Shantou 515063, China

E-mail: akhil@stu.edu.cn

Xiaodong NIU, Qiujuan ZHANG

Shantou Ruixiang Mould Co. Ltd., Jinping S\&T Park, Shantou 515064, China

Surinder SINGH, Harpreet SINGH

Department of Mechanical Engineering, Indian Institute of Technology Ropar, Rupnagar 140001, India

Biranchi PANDA

IDMEC, Instituto Superior Técnico, Universidade de Lisboa, 1649-004 Lisboa, Portugal can help experts select the ideal type of process or technology for the manufacturing of elements composed of a given alloy or material $(\mathrm{Ni}, \mathrm{Ti}, \mathrm{Al}, \mathrm{Pb}$, and stainless steel).

Keywords direct metal deposition, laser-based manufacturing, rapid manufacturing, selective laser melting, additive manufacturing

\section{Introduction}

The two main challenges faced by the product manufacturing industry are substantial reduction of product development time and improvement in flexibility for manufacturing various types of products [1,2]. Computer-aided design and manufacturing (CAD and CAM), which have remarkably improved production design and manufacturing stages, are used for this purpose. However, actual integration of CAD and CAM is impracticable for the rapid development of products. Research on computer numerical control (CNC) programming, process planning, and feature recognition has been conducted to achieve actual integration, but the gap between CAD and CAM remains unfulfilled. Although products obtained from $\mathrm{CNC}$ machining have high geometric and material quality, their implementation requires substantial human intervention during path planning. The two main aspects where CAD and CAM are ineffective are rapid creation of threedimensional (3D) models and cost-effective production of patterns and molds with complex shapes [3]. The demand for reduced product development time and product life cycle has resulted in the emergence of a new paradigm called rapid prototyping (RP) [4-7].

$\mathrm{RP}$, which is also referred to as layered manufacturing (LM), has been utilized to form near-net-shape objects directly from CAD file sources [8,9]. LM offers total automation of virtual models into physical ones. This automation is achieved by slicing a 3D geometric model 
into layers and realizing each layer at a time. RP was originally developed for the fabrication of prototype models. However, several attempts have been made to manufacture actual products by LM [9-12]. Various RP technologies, such as fused deposition modeling, selective laser sintering (SLS), stereo-lithography (SLA), and 3D printing (3DP), have been adopted to manufacture components [13-19]. These technologies use plastic, paper, wax, polymer, and temperature powder materials to fabricate parts. The properties of these parts do not satisfy the requirement of end-use-material functional products. Moreover, the application domain of metallic prototypes is larger than that of plastic prototypes [20]. Researchers have focused on overcoming the shortcomings of RP to achieve additive manufacturing (AM) by adopting various procedures, such as using multiple tool heads, rapid motions and processes, material variety, hybrid systems, computer-aided process planning, and conformal LM using nanotechnology [20-23]. Different from those in traditional manufacturing processes, complex-geometry components can be easily manufactured by AM techniques; these components were previously considered economically unfeasible to manufacture directly [24]. The steps involved in AM are presented in Fig. 1.

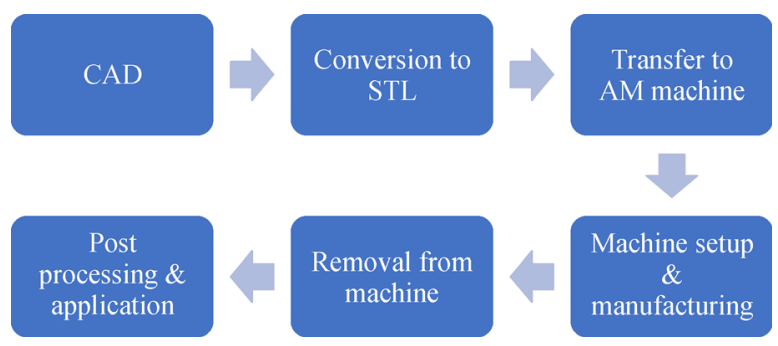

Fig. 1 Schematic of the process of AM to produce parts. STL: Standard Template Library. Reproduced from Ref. [25]

AM deploys RP processes to produce end-use items directly from CAD data. AM is considered an extension of $\mathrm{RP}$ and rapid tooling (RT), and its main purpose is to manufacture functional products through processes similar to those of RP while using actual materials required by the design of such products. Direct deposition of metallic powder in AM has led to the shift from plastic prototypes to metallic parts. As-produced parts from AM can be directly used for the required functions. However, difficulties have to be addressed to manufacture standalone parts through AM. Oxidation of input materials, such as copper and aluminum, during melting in AM is challenging. Geometrical accuracy from a model to an actual part is another chief difficulty faced by AM industries. Mechanical properties such as cohesion strength, tensile strength, anisotropic behavior, and surface roughness, also pose challenges to AM of metallic parts [24]. Considerable effort has been exerted to extend or modify existing LMbased technologies. As a result, AM technologies have been developed to fabricate metallic objects; these technologies are categorized as powder bed fusion, including selective laser melting (SLM), direct metal laser sintering (DMLS), and SLS, and as directed energy deposition, such as direct metal deposition (DMD), laser cladding (LC), laser-engineered net shaping (LENS), shape metal deposition (SMD), hybrid layered manufacturing (HLM), and laser metal forming (LMF) [26-35].

AM-based technologies are utilized to manufacture direct end-to-use parts, which are composed of nickel, titanium, aluminum, lead, and stainless steel alloys. These alloys have unique characteristics of low weight, high strength, high oxidation resistance, high biocompatibility, and low elastic modulus. The present work reviews the type of materials used in laser-based AM processes for the manufacturing of metallic products. The advantages and disadvantages of processes and different materials are summarized.

The remainder of the paper is structured as follows. Section 2 discusses the applications of processes that use metal alloy materials, such as titanium, stainless steel, nickel, aluminum, and lead, in the fabrication of metallic products. Section 3 discusses existing issues and highlights future research directions.

\section{Application of metallic powders used in various AM processes}

Levy et al. [34] classified material-dependent AM processes and discussed the characteristics of processoriented metal part manufacturing techniques and materials. Metal part manufacturing techniques were classified as melting and non-melting. For the categorized processes, the properties of metal products formed from the materials used were discussed. Karunakaran et al. [32] classified rapid manufacturing (RM) processes as direct and indirect. Direct-based processes were further classified as powder bed, deposition, and laminated tooling. Laeng et al. [36] rigorously reviewed the LMF processes for RP. Process and laser parameters, software, hardware, materials, costs, and process limitations were discussed. Bernard et al. [37] discussed existing and emerging AM processes for the manufacture of metallic objects. The shortcomings of RP for fabricating metallic objects and the route for overcoming these problems were presented. Various alternatives for rapid manufacturing technologies, such as powder bed technologies (SLS, 3DP), layer-based layered deposition technologies, material translation technologies, laminated manufacturing, and direct mold technologies, were discussed in detail. Ferreira et al. [38] rigorously reviewed the state of rapid metal casting technologies and provided a 
strategy framework and other RT and AM methods. AM technologies extensively use metallic materials to form high-quality functional parts. The materials can be in powder, wire, or metal sheet form $[39,40]$. The various process parameters of laser-assisted additive manufacturing (LAAM) that affect the quality of manufactured products are presented in Fig. 2 [41]. A few of these parameters are discussed below, and the rest are discussed under each section according to alloy behavior.

The authors concluded that heat accumulation in a melt pool occur when a small hatch spacing is used because it forms a homogenous and continuous layer due to the gradual cooling process. Low speeds favor the formation of metallurgical pores, whereas high scanning speeds form keyhole pores. Singh et al. [42] studied the effect of heat input and temperature on the microstructure of laser-clad copper. They concluded that the temperature of the weld pool increases with the increase in laser power/heat input. The penetration depth of the weld pool increases with the temperature of the weld pool, thereby increasing the grain size of the previously deposited layer. Islam et al. [43] discovered that an energy input of $1000 \mathrm{~J} / \mathrm{mm}^{3}$ maximizes temperature and the absorption of laser power due to the rapid increase in temperature with an initial increase in energy input. Further energy input causes laser beam reflection from the melt pool, which reduces the process temperature.

The present work also reviews the applications of various materials used in different $\mathrm{AM} / \mathrm{RM}$ processes. The materials under review include nickel, titanium, aluminum, lead, stainless steel, and other alloys. These materials have unique characteristics of high strength-to-weight ratio, high oxidation resistance, high biocompatibility, and low elastic modulus, making them promising candidate materials for several engineering applications.

\subsection{Ti-based alloy (Ti-6Al-4V)}

Ti-based alloys are used for several applications, such as aerospace and bio-medical devices/implants, due to their excellent strength-to-weight ratio, superior biocompatibility, low elastic modulus, and exceptional corrosion resistance [44-46]. Srivastava and Pavel [47] investigated the grinding of Ti-6Al-4V parts produced through laser sintering. Baufeld et al. [48] applied SMD to fabricate Ti$6 \mathrm{Al}-4 \mathrm{~V}$ components and investigated the texture and crystalline correlations of the microstructure of the components. RP technology assisted with high-power fiber lasers were used to fabricate wire-based alloy Ti-6Al$4 \mathrm{~V}$ parts [49-51]. The following process parameters were investigated: Relative position between the wire feeding system and substrate and laser beam-to-wire width ratio. The results showed that the former affects the molten metal transfer rate, and the latter affects process efficiency. The fabricated part was free of defects and had lower melting efficiency than the other RP processes. Gibson et al. [52] compared the two processes of AM, namely, electron beam melting (EBM) and SLM, for producing Ti-based alloys, and the comparison is shown in Table 1 [52]. EBM in combination with SLM or SLS can additively manufacture a part with enhanced properties compared with other conventional methods. Cylindrical components made of Ti-based alloy Ti-6Al-4V have also been fabricated using RP technologies assisted with high-power fiber laser [53]. The properties of the formed cylindrical part were compared with those of other related processes, and the results showed that using high-power fiber laser produces high-density parts and consumes less time. Biffi et al. [54] was the first to produce a $\mathrm{TiCr} 1.78$ compound through SLM. Premixed and pre-alloyed prototype powders of Ti-Cr compositions were prepared and investigated. The

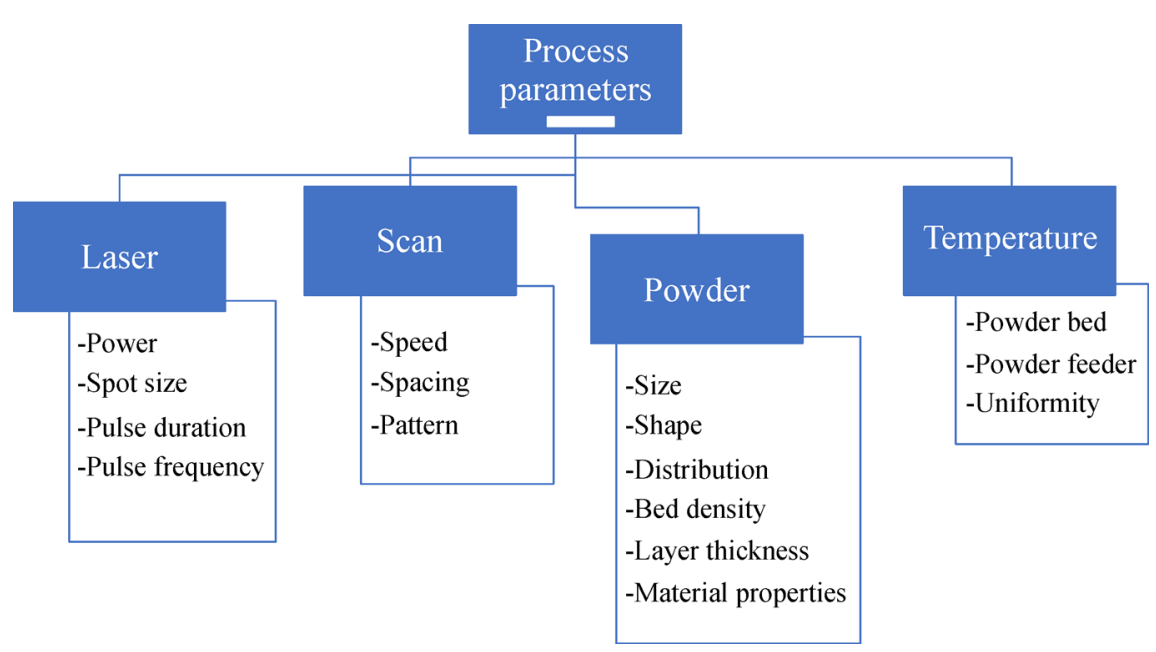

Fig. 2 Various process parameters of LAAM that affect the properties of manufactured products. Reproduced from Ref. [41] 
Table 1 Comparison of the properties of parts produced by EBM and SLM [52]

\begin{tabular}{lcc}
\hline Characteristic & EBM & SLM \\
\hline Thermal source & Electron beam & Laser \\
Atmosphere & Vacuum & Inert gas \\
Scanning & Deflection coils & Galvanometers \\
Energy absorption & Conductivity limited & Absorptivity limited \\
Powder pre-heating & Use electron beam & Use infrared heaters \\
Scan speeds & Very fast, magnetically & Limited by \\
& driven & galvanometer inertia \\
Energy costs & Moderate & High \\
Surface finish & Moderate to poor & Excellent to moderate \\
Feature resolution & Moderate & Excellent \\
Materials & Metal (conductors) & Polymers, metals, ceramics \\
\hline
\end{tabular}

pre-alloyed powders allowed the formation of Laves phases in the SLM parts. Complete reaction was not observed in the pre-mixed powders. However, a strict correlation was noted between the relative density of the SLM parts and the energy density.

Simulation-based studies have also been performed on various Ti alloys. Rolchigo and LeSar [55] established a cellular automata model for coupled solute transport and growth of cellular and dendritic $\beta$-Ti alloy colonies under thermal conditions typically encountered in AM processes. Mizuta et al. [56] designed a computer-aided 3D micro welder (3DMW) and applied it in intermetallic coating. A thin piece of aluminum wire was fed into a $\mathrm{Ti}$ substrate surface, and the spark was ignited by a thin electrode of $\mathrm{W}-\mathrm{Ce}_{2} \mathrm{O}_{3}$ alloy to form layers of $\mathrm{Ti}$ aluminides. The Vickers hardness and wear resistance of the formed product were remarkably improved. A similar application of 3DMW to the free-form fabrication of Ti-based and intermetallic alloys at the microscale was studied by Katou et al. [57]. Rahmati et al. [58] fabricated Ti-based alloy dental implant restorations using RP technology and investment casting. A stress analysis of dental implants was performed using the finite element method (FEM) to verify different loading conditions along the implant surfaces. The results of FEM satisfied the different loading conditions. Sing et al. [59] used SLM to fabricate titaniumtantalum (TiTa) alloy comprising $50 \mathrm{wt} \%$ of each element for the manufacturing of bio-implant samples. This alloy has a potential for use in biomedical applications due to its higher strength-to-modulus ratio than Ti-6Al-4V and commercially pure titanium. A comparison of the various AM techniques used to manufacture Ti-based alloys is summarized in Table 2.

\subsection{Stainless steel-based alloys}

Wu et al. [60], Everton et al. [61], and Fayazfar et al. [62] conducted reviews of the use of stainless steel powder as
Table 2 Comparison of various techniques used to additively manufacture Ti-based alloys

\begin{tabular}{lc}
\hline Technique & Advantages and disadvantages \\
\hline $\begin{array}{l}\text { RP with high power } \\
\text { laser fibres }\end{array}$ & $\begin{array}{r}\text { Free of defects, lower melting efficiency with respect } \\
\text { to other LM processes. }\end{array}$ \\
EBM & $\begin{array}{r}20 \%-80 \% \text { higher elongation, hardness; } \\
\text { high density parts made in lesser time when high } \\
\text { power fibre lasers are used. }\end{array}$ \\
3DMW & $\begin{array}{r}\text { Improved Vickers hardness and wear resistance. } \\
\text { SLS }\end{array}$ \\
SLM & $\begin{array}{r}\text { Hetter bio-compatibility for tantalum and titanium } \\
\text { alloys as compared to Ti-6Al-4V. }\end{array}$ \\
\hline
\end{tabular}

the feedstock material in AM. Charmeux et al. [63] investigated the performance of three process chains for vacuum investment casting of aluminum/zinc alloys and stainless steel parts. The property parameters considered were dimensional accuracy, surface quality, and production costs of the three process chains. The first two process chains employed the classical lost wax process and LM technologies to create patterns out of a thermoplastic material, and the third process chain used F-cubic to directly produce casting in zirconia ceramics. Bibb et al. [64] applied SLM to produce 316 stainless steel customfitting surgical guides. The guides produced had superior rigidity and enhanced wear resistance. The guides were cost effective and convenient to sterilize using standard autoclave procedures. Aiyiti et al. [65] developed microplasma arc welding to fabricate ER308L stainless steel parts and examined the tensile strength, surface roughness, and elongation of parts. They found that the current process can build fully dense parts with low costs. España et al. [66] performed laser surface modification by applying brass coating on AISI 410 stainless steel using high-power laser in LENS. The influence of brass coating on interfacial microstructure and thermal performance was evaluated. The thermal conductivity and performance of AISI 410 stainless steel improved by $38 \%$ and $54 \%$, respectively. The absence of a sharp interface between the coating and substrate resulted in low interfacial thermal contact resistance. The convective heat transfer rate of AISI 410 stainless steel also increased by $21 \%$. Joo and Baldwin [67] developed an embedded-active approach for micro-system packaging to reduce manufacturing costs, lead time, and process complexity. RP of a micro-system packaging was achieved through a data-driven chip-first packaging process using direct printing of metal nanoparticles. The process involved embedding of a bar dice into a copper or stainless-steel substrate, and the gap was filled with thermoplastic adhesives. The developed process eliminated the use of photomasks and flip chip folder bumps for circuit patterning; thus, micro-system packaging was characterized by high density and low cost. Qi et al. [68] modified the scanning mode of electron beam selective melting (EBSM) by combining split and rotating 
mode with the zig zag mode. On the basis of this modified mode, parts of 316L stainless steel powder were fabricated using EBSM. Deng et al. [69] fabricated fully compacted 316L stainless steel metal parts using SLM and analyzed the tensile strength and inner microstructure of the parts. They found that the parts from SLM were free from cracks and defects, and tensile strength was higher than that of 316L stainless steel casting parts. Fu et al. [70] designed a new micro powder injection modeling apparatus for the fabrication of $316 \mathrm{~L}$ stainless steel micro-structures with a high aspect ratio. The advantage of the apparatus was realtime monitoring and rapid adjustment of the mold cavity temperature, which make the molding and demolding of green micro-structures with high aspect ratios possible. The melt fills the micro-cavity with a small heat loss, thereby filling the micro-cavities and producing parts with reduced dimensions. Ghany and Moustafa [71] thoroughly compared the capabilities and product quality of four AM systems. The AM systems considered for the study were M3 linear (based on micro-welding technology), 3D systems (based on SLS), electro optical systems (based on DMLS), and MCP-HEK (based on SLM), and the materials considered were CL 50 WS (hot work steel), laser form A6 (steel based), DSH20 (high-strength steel), and stainless-steel powder, respectively. The metrics adopted for comparison were benchmark geometry, dimensional precision, material type, product strength and hardness, surface quality, building speed materials, and operation costs. The comparative analysis revealed that AM technology is successful in producing metallic products and can create complicated-geometry products, cooling tubes, and thin walls. The product with the best quality and strength was provided by the AM technique based on melting/micro-welding. In addition to the experimental work on AM of stainless steel alloys, several simulation studies were conducted by various researchers by using various software tools. Mughal et al. [72] developed a 3D finite element thermo-mechanical model to predict induced residual stress deformations associated with molten metal deposition applied to layer manufacturing with specific application to gas metallic arc welding (GMAW). The material used was mild steel with temperature-dependent material properties and was mod- eled as elastic perfectly plastic. The finite element model predictions for deformations, temperatures, and fusion zone were consistent with the experimental data. Casavola et al. [73] also applied SLM and investigated the residual stresses of AISI Marage 300 steel specimens. A statistical analysis was performed to establish the relationship among sample position, distance from the specimen surface, and principal residual stresses. The experiment results showed that high thermal residual stresses were generated during the melting/solidification stage in SLM parts. Costa et al. [74] developed a solid free-form fabrication technique to laser consolidate AISI H13 steel powders into fully dense 3D shapes. The produced items had a relatively poor surface finish. The developed technique does not require complex laser powder deposition (LPD), a powder feeding nozzle, and powder scrappers and rollers and can be used with all materials processed with SLS, EBM, and LPD. Recent studies in this area [62,75-81] include investigations of the effect of process parameters on the microstructural and physical properties of $316 \mathrm{~L}$ stainless steel parts manufactured through SLM. Tucho et al. [79] investigated the porosity levels of SLM-manufactured SS $316 \mathrm{~L}$ parts. The porosity levels were measured in consideration of the microstructure and material hardness of stainless steel. Bartolomeu et al. [80] concluded that wear resistance, hardness, and tensile and yield strengths are the highest in SLM parts. These parameters were measured against conventional casting and hot-pressing methods. The increase in material properties was due to the relatively fine microstructure of the SLM parts. Researchers have also utilized SLS to improve the bio-functionality of stainless steels $[81,82]$. Kong et al. [81] investigated the effect of 3DP laser power on the microstructure, biocompatibility, and mechanical and corrosion properties of SLM 316L. The SLM 316L parts formed at a high laser power showed improved elongation, corrosion resistance, and biocompatibility. On the contrary, using low laser power resulted in poor performance and instability in the long-term experiments on simulated body fluid. The efficacy of reduced-dimension parameter groupings was thus confirmed. Shamsaei et al. [83] confirmed that specific energy is important in quantifying many laser and welding processes with regard to their bonding strength and joint/

Table 3 Comparison of various AM techniques used to manufacture stainless steel-based alloy products

\begin{tabular}{lc}
\hline Technique & Advantages and disadvantages \\
\hline SLM & $\begin{array}{c}\text { Comparable to other LM processes with regard to time, cost but have higher rigidity } \\
\text { and wear resistance. Parts are free from cracks, defects with higher tensile strength, } \\
\text { high thermal stresses generated during melting/solidification. }\end{array}$ \\
$\begin{array}{l}\text { Laser surface modification in LENS } \\
\text { Micro powder injection }\end{array}$ & $\begin{array}{c}\text { Real time monitoring, rapid mold adjustment makes molding of high aspect } \\
\text { green micro-structures possible, made with lower heat loss. }\end{array}$ \\
$\begin{array}{l}\text { RP machine: Micro welding M3 linear, } \\
\text { 3D (SLS), EOS (DLSM), MCP-HEK (SLM) }\end{array}$ & $\begin{array}{c}\text { RPM can make complicated geometry products, cooling tubes and thin walls, } \\
\text { with the best quality and strength from M3 linear. Poor surface finish, } \\
\text { but can be used with all materials processed by SLS, EBM, and LPD. }\end{array}$
\end{tabular}


layer resistance to failure (collapsing). A comparison of various AM techniques used to manufacture stainless steelbased alloy products is presented in Table 3.

\subsection{Nickel-based alloy (Ni-based alloy)}

An extensive review of the mechanical properties of the metal-based AM process was conducted by Segerstark et al. [84] and Lewandowski and Seifi [85]. Qian et al. [86] proposed a hybrid plasma-laser deposition manufacturing (PLDM) process to fabricate Ni-based alloy parts. The parts produced using this new method were fully dense, had high strength and porosity, and were free of cracks and strongly bonded. Thus, the proposed method improved part accuracy and surface state. Dinda et al. [87] used DMD to fabricate a series of Ni-based super alloy Inconel 625 samples. The alloy was selected due to its good creep and fatigue strength, high corrosion resistance, and good weldability and fabricability. The formed samples were free from defects such as cracks, porosity, and bonding error. Horii et al. [88] proposed a 3DMW method to fabricate 3D objects made of Inconel alloy 600. The alloy was selected because of its high oxidation resistance and strength. The mechanical properties of the product formed, including hardness, elongation, density, and strength of the formed object, were comparable to those of commercial superalloys. The objects formed were fully dense and free from cracks and pores, and their properties satisfy the Japanese standard industrial code. Minagawa et al. [89] illustrated the application of a $3 \mathrm{D}$ inkjet printing system to the fabrication of metallic parts. The material used was carbonyl nickel powder, and two approaches of fabrication via the use of a binder directly and indirectly were adopted. The variation in microstructure was studied, and the results showed that the part formed by using a binder directly has an inhomogeneous structure and a non-uniform density distribution, whereas the part formed by using a binder indirectly has a homogenous structure, high density, and high strength. Models of a die, an artificial bone, and a dental crown were also fabricated by SLM [90]. The material for SLM was based on a single scanning test. Ni-based alloy, pure Ti powders, and Fe alloy were found to be appropriate materials. The densities of the SLM parts were $90 \%$ higher than that of the solid model. Angelastro et al. [91] used direct laser metal deposition (DLMD) to fabricate dense metallic parts. $\mathrm{A} \mathrm{CO}_{2}$ laser machine with a maximum power of $3 \mathrm{~kW}$ was used to perform the experiment. The material utilized was Colmonoy 227-F, a nickel alloy specially designed for glass mold protection and restoration. The performance of the DLMD process was examined in terms of hardness, porosity, microstructure, and composition of a part. Gordon et al. [92] introduced a new hybrid material by electroforming nanocrystalline $\mathrm{Ni}$ around a rapid prototyped acrylic photopolymer micro-truss to combine the high ultrastrength gained by a reduction from grain size scale to nanometer scale and the structural efficiency of the microtruss. The density of the new hybrid material was $1.5 \%$ $5 \%$ of the bulk nanocrystalline $\mathrm{Ni}$, and the elastic modulus and peak strength increased by $350 \%$ and $500 \%$, respectively. The experimental knockdown factors were determined by subjecting the strut thickness to uniaxial compression for developing the mechanical properties of the nanocrystalline micro-truss materials. Dressler et al. [93] compared the temperature distribution of objects formed from metal and ceramic powders during 3DP. The metal powder was composed of iron, chromium, nickel, copper, and molybdenum. The ceramic powder with the same particle size as the metal powder was composed of potassium, calcium, sodium, and phosphate ion. Both powders were characterized in terms of thermal conductivity, thermal diffusivity, emissivity spectra, and density. No difference was found in their steady-state maximum temperature and maximum achievable temperature. The only difference was in the transient temperature evolution. The results were subsequently verified through numerical simulation. Hanumaiah and Ravi [94] investigated the capabilities (straightness, flatness, and circularity) of two widely used RT processes, namely, DMLS and SLA. The material used for the former was copper nickel-based EOS direct Metal-50 powder and that used for the latter was SL5170 photopolymer resin. A sampling technique based on region elimination adaptive search was proposed to estimate the form tolerance. The study concluded that the form accuracy of SLA samples was relatively poor, but their dimensional accuracy was better than that of DMLS. Several current studies $[95,96]$ have included the investigation of properties for nickel-coated Al 7050 alloy. Bi and Gasser [97] investigated the restoration of nickelbased turbine blade knife edges with controlled LAAM and concluded that the LAAM process is feasible for the reconditioning of gas turbine blade knife edges. Kanagarajah et al. [98] compared SLM-processed Inconel 939 with conventional cast alloy. Heat treatment affected the two differently, and microstructural differences were found in the SLM part. The fact that its mechanical performance was satisfactory reveals the technique's potential in producing complex parts suited for hightemperature applications. Nie et al. [99] developed a multiscale model that combines FEM and stochastic analysis to simulate the evolution of the microstructure of an $\mathrm{Nb}$-bearing Ni-based superalloy during laser AM solidification. The developed model developed correlated dendrite nucleation and growth, $\mathrm{Nb}$ segregation, and the formation of the Laves phase to the solidification conditions and resulting microstructure. A small equiaxed dendrite arm spacing under high cooling rates and low temperature gradient to growth rate ratios was found to be especially effective for the formation of the Laves phase. The converse conditions produced continuously distributed coarse Laves phase particles, which negatively affected the metal's mechanical properties. Sateesh et al. 
[100] used DMLS AM-based IN625 metal matrix composites to investigate the effect of laser scan speed on the metal's microstructure and mechanical properties. The microstructure became more refined as the laser scan speed increased, and the resulting grain shape was cellular equiaxed. Increased porosity at high scan speeds resulted in reduced densities and hardness. Marattukalam et al. [101] studied the dependence of microstructure, phase constituents, hardness, and corrosion properties on laser power and scan speed. The study was performed on laserprocessed NiTi alloy. Large amounts of high-temperature austenite were retained at room temperature due to the high cooling rates resulting from the laser processing. The austenite formed increased the hardness, and laser power was directly related to grain size and corrosion resistance (increased the grain size and corrosion resistance). Hong et al. [102] applied laser melting deposition AM to synthesize Inconel 625 composites with ultrafine TiC particles. The study focused on microstructure development, densification response, wear performance, tensile properties, and other mechanical properties and their relation to laser input energy per unit length. Klapper et al. [103] investigated pitting corrosion in additively manufactured $\mathrm{Ni}$ alloy in an environment of chloride components. A complete study of direct laser deposition for AM was conducted by Shamsaei et al. [83]. They revealed the mechanical behavior and compared it with that of conventional methods. Investigations for process parameter optimization and control have also been conducted. A comparison of the various AM techniques used to manufacture Ni-based alloy parts is provided in Table 4.

Table 4 Comparison of various additive manufacturing techniques used to manufacture Ni-based alloy parts

\begin{tabular}{lc}
\hline Technique & Advantages and disadvantages \\
\hline DMD & $\begin{array}{c}\text { Free from cracks, porosity and bonding } \\
\text { error for Inconel } 625 .\end{array}$ \\
3DMW & $\begin{array}{c}\text { Used on Inconel 600. Hardness, elongation, } \\
\text { density and strength comparable to } \\
\text { commercial super alloy. }\end{array}$ \\
SLM & $\begin{array}{c}90 \% \text { higher density, most of the metals, } \\
\text { high strength. Better dimensional accuracy. } \\
\text { 3DP on powder mix of } \\
\text { Fe, Cr, Ni, Cu, and } \mathrm{Mo}\end{array}$ \\
\hline
\end{tabular}

\subsection{Al-based alloy}

A thorough review of SLS/SLM for Al alloy powders was conducted by Olakanmi et al. [104]. Bassoli and Atzeni [105] performed extensive experiments to study the effect of heat treatment parameters (temperature and time) on the mechanical properties of cylindrical Zcast metal parts manufactured using Zcast direct metal casting. The mechanical properties studied were dimensional accuracy and compressive strength. The researchers found that temperature significantly affected the compressive strength of the part, but none of the heat treatment parameters affected dimensional accuracy. Bassoli et al. [106] evaluated the dimensional accuracy and feasibility of two rapid casting solutions based on 3DP technologies, investment casting, and Zcast process for the fabrication of light cast Al alloys. The two rapid casting solutions effectively produced technological prototypes in reduced time and with low costs, and dimensional tolerances were completely consistent with those of the metal casting process. Gill and Kaplas [107] conducted a similar comparison of two rapid casting technologies based on 3DP, Zcast process, and investment casting for the casting of $\mathrm{Al}$ alloy. Important mechanical properties were compared, and the results were supported by microphotographs and radiography analysis. A metal matrix composite electrode used in electro discharge machining was fabricated by mixing copper powder with aluminum oxide powder using RP technology [17]. RP technology was adopted due to its capability to fabricate complex shapes from a CAD model directly involving low production costs. Kang and Ahn [108] fabricated a microchip made of Al powder and compared the precision and cost efficiency of three processes, namely, mechanical micromachining, microelectromechanical system (MEMS) techniques, and injection molding. They observed that injection molding has approximately 15 times lower cost than the MEMS method, and mechanical micromachining is a simple, rapid, cost-effective method of fabricating the metal master for polymer microchips. Pal et al. [109] presented methodologies for computer-aided reverse engineering with the help of a case study of an $\mathrm{Al}$ alloy separator body of a hydraulic filter assembly for a special army vehicle. They found that the fabrication of wax patterns directly from 3D CAD data in a thermojet system, followed by investment casting, provides a reliable and economic route for the development of intricate parts for replacement purposes. Hsu et al. [110] applied investment casting and injection molding to the RP/RT process to obtain metal (Al-Si) and plastic (acrylonitrile butadiene styrene (ABS)) propellers. These processes were compared by following the RP master model. RT combined with CNC machining reduced the processing time by $17 \%-20 \%$, and the cost was reduced by $55 \%-61 \%$. The proposed process is helpful in obtaining special shapes of products, when a material requires a large amount of cutting, or when expensive and hard-to-machine materials are used. Mondal et al. [111] fabricated SiC-reinforced particulate metal matrix composites of $\mathrm{Al}$ alloy through $\mathrm{RP}$-integrated investment casting. The mechanical properties and microstructure of the formed product were studied. The researchers found that fluidity was reduced due to the increase in melt viscosity given the incorporation of particulates. Yan et al. [112] studied the microstructure and mechanical properties of DMLS-synthesized AlSi10Mg. 
This task was performed over a wide range of volume fractions (5\%-20\%) and unit cell sizes (3-7 $\mathrm{mm}$ ). $\mathrm{Al}_{85} \mathrm{Nd}_{8} \mathrm{Ni}_{5} \mathrm{Co}_{2}$ samples with high bulk strength and thermal stability were prepared by SLM by Prashanth et al. [113]. The samples had a microstructure similar to that of a composite, with submicron-sized stable intermetallic phases dispersed in an Al matrix. This microstructure resulted in high compressive strength between $303 \mathrm{~K}$ and $573 \mathrm{~K}$. The researchers concluded that SLM is a viable alternative for the production of dense, thermally stable, and near-net-shaped components from highstrength Al alloys. Kenel et al. [114] combined in situ synchrotron micro-XRD, small angle X-ray scattering, and laser-based heating and rapid cooling to study alloy behavior under AM comparable processing conditions. Cabrini et al. [115] used DMLS-processed Al alloy to perform potentiodynamic and electrochemical impedance spectroscopy tests. Recently, artificial neural networks [116] were utilized to determine the relationship between laser metal deposition process parameters and the resulting geometrical parameter of the deposited metal trace. This task was performed on $5 \mathrm{~mm}$ thick $2024 \mathrm{Al}$ plates. The neural network-based technique was effective in predicting appropriate process parameters and resulted in the required geometry for the deposited metal trace. The SLM process induced thermal residual stress in the manufacturing part, which necessitated the use of metal anchors and other support structures to bind components to a substrate plate and thus minimized geometric distortion or warp. This condition limited the geometric freedom of the process and made post-processing necessary. The development of residual stresses and the use of anchors were eliminated by using anchorless SLM [117]. These were achieved by maintaining the material in a stress-relieved state for the duration of the build. A comparison of the various AM techniques used to manufacture Al-based alloy parts is presented in Table 5.

Table 5 Comparison of various AM techniques used to manufacture Al-based alloy products

\begin{tabular}{lc}
\hline Technique & Advantages and disadvantages \\
\hline Rapid casting based on 3DP & $\begin{array}{c}\text { Prototyping done in lesser times with } \\
\text { lower costs, dimensional tolerances } \\
\text { within metal casting limits. } \\
\text { Preferred to make complex shapes from } \\
\text { CAD with lower production costs. }\end{array}$ \\
$\begin{array}{l}\text { RP with integrated } \\
\text { investment casting process }\end{array}$ & $\begin{array}{c}\text { Reduced fluidity due to viscosity } \\
\text { increase of the melt. }\end{array}$ \\
Anchorless SLM & $\begin{array}{c}\text { Reduced residual stresses, better geometric } \\
\text { tolerances for overhanging geometries, no } \\
\text { anchoring is required for holding. }\end{array}$ \\
\hline
\end{tabular}

\subsection{Lead-based alloy and other materials}

3D printed circuits of lead $(\mathrm{Pb})$-based alloy was fabricated using a direct RP printing machine and polycaprolactone deposited in the crossing points of the circuit to insulate the printed line $[118,119]$. The RP printing process helped reduce the size of the board by $34 \%$. Gao et al. [120] developed an apparatus that can make mono-sized metal spheres by vibrating the breakup of droplets. The apparatus can be used in many applications, such as solder ball manufacturing, circuit board printing, and rapid prototype manufacturing. Uniform-sized tin powders were obtained after cooling and solidification of droplets. A similar application of droplet-based manufacturing was discussed by Hsiao et al. [121], who investigated the effect of surface roughness on the bouncing of liquid droplets from the substrate. In their work, an experiment was conducted to image the deposition behavior of $\mathrm{Pb}-37 \mathrm{wt} \%$ droplets on Au-plated substrates. The analytical model showed that the bouncing of liquid droplets from the surface increased with the increase in surface roughness.

Aghanajafi and Daneshmand [122] employed 3DP technology to fabricate airfoil and compared its performance (surface quality, dimensional accuracy, and aerodynamic coefficients) with that of a metal model manufactured using traditional methods. A significant difference was found in the aerodynamic coefficients of the airfoil produced from the methods, which revealed that the current technology can replace existing traditional methods because it requires less time and is less expensive. Baptista et al. [123] developed a modular tool concept in which active stamping tools (punch, die, and blank holder) were developed using various RT techniques, such as DMLS, lights out management, and hardware security modules (HSM). Shells produced using stereolithography were utilized to fabricate inserts in the stamping tools. SLS was applied to manufacture homogenous and functional graded polyamide specimens, and the energy density level was changed to control porosity in the specimens. The influence of energy density level on the mechanical responses, ultimate tensile strengths, and rupture strengths of the produced specimens were studied. SLS showed a considerable advantage of producing functionally graded porous specimens with controlled variations in physical and mechanical properties. Some work related to the comparison and study of robot path generating methods has also been performed to manufacture fully dense complex shapes by metal deposition. Karunakaran et al. [124] developed arc HLM for fabricating near-net-shape components by combining features of weld deposition using arc welding and finishing on a CNC machine. The arc welding unit was integrated into the $\mathrm{CNC}$ machine to carry out the process. The formed products had a smooth finish, were fully dense, and were obtained with reduced costs and time. Milovanovic et al. [125] studied the feasibility of using DMLS in RT of tire tread ring molds. The study concluded that DMLS is time and cost saving compared with conventional methods and thus makes new tire development and testing easy and fast. Pacurar et al. [126] developed a new post-processing method to improve 
the mechanical properties (reduce porosity) of injection molding tools manufactured through SLS. The new method outperformed the classical method of post processing SLS parts in an oven. Piqué et al. [127] introduced laser-based digital microfabrication processes and the types of devices and structures that can be fabricated from these. These processes were found to be compatible with a wide range of materials, surface chemistries, and surface morphologies and were well suited for the production of microelectronic devices and micro components (antennas, sensors, power sources, and passives). A similar application of a laser-based digital fabrication technique, laser direct-wire, was discussed by Piqué and Chrisey [128] for the fabrication of microelectronic devices. A new software called Elecform $3 \mathrm{D}^{\mathrm{TM}}$ was developed to reduce the non-uniformity of metal deposition [129]. This software is user friendly because it simulates and calculates the optimal positions of the cathode on the basis of the electrolytic parameters of the bath. The software, when hybridized with a 3D printer, produces high-quality metallic parts comparable to those of SLS-SLM technologies and HSM. Meier and Haberland [130] discussed the properties of SLM metallic parts and evaluated the process parameters that influence these properties. Metal parts made of Laserform St-100 powder were fabricated through SLS [131]. A property of the formed part, shrinkage ratio, was measured, and the influence of the process parameters on shrinkage ratio was determined using the design of experiment method. The Taguchi method was used to determine the optimal process parameters for manufacturing SLS metal parts in an efficient manner. Chen et al. [132] developed a new powder feeding system by utilizing an ultrasonic device to deposit micron powder particles on a substrate. The experimental parameters of the selective laser micro sintering process were optimized, and 3D micro parts were sintered with micron powder. Chen et al. [133] compared the structure performance of metal parts fabricated by direct laser fabrication via $\mathrm{CO}_{2}$ and $\mathrm{Nd}$ :YAG lasers. The metal part fabricated using the Nd:YAG laser had high intensity, fine crystalline grains, and an oriented solidification structure; it also had lower plasticity than the part fabricated using the $\mathrm{CO}_{2}$ laser. Dingal et al. [134] applied the Taguchi method (L8 design) to investigate the effect of process parameters on the density, porosity, and hardness of SLS parts made of iron powder. All of the process parameters significantly affected the three responses of the parts. A comparison of the various $\mathrm{AM}$ techniques used to manufacture $\mathrm{Pb}$ based alloy parts is presented in Table 6 .

In addition to these alloys, thick pure copper coatings have also been developed on SS316 steel substrates by using LC techniques for application in nuclear tokamaks and manufacturing of copper-cast iron canisters Ref. [42]. Singh et al. [42] developed and characterized thick copper coatings developed by LC and cold spraying. They
Table 6 Comparison of the various additive manufacturing techniques used to manufacture lead-based alloy parts

\begin{tabular}{|c|c|}
\hline Technique & Advantages and disadvantages \\
\hline Direct RP printing & $\begin{array}{l}\text { Used in 3D printed circuits. } \\
\text { Size reduction of } 34 \% \text {. }\end{array}$ \\
\hline $3 \mathrm{DP}$ & $\begin{array}{l}\text { Significant difference in aerodynamic coeffi- } \\
\text { cients of fabricated airfoil, lower time and cost } \\
\text { expended. Using Elecform, makes products } \\
\text { comparable to SLS/SLM, HSM parts. }\end{array}$ \\
\hline SLS & $\begin{array}{l}\text { Can produce functionally graded porous } \\
\text { specimens with controlled variations in } \\
\text { physical and mechanical properties. } \\
\text { Reduced porosity in injection molded parts, } \\
\text { better process than oven post processing. }\end{array}$ \\
\hline $\begin{array}{l}\text { DMLS for RT of tyre tread } \\
\text { ring mould }\end{array}$ & $\begin{array}{l}\text { Saves time, cost aiding in tyre } \\
\text { testing and development. }\end{array}$ \\
\hline $\begin{array}{l}\text { Laser-based digital } \\
\text { microfabrication }\end{array}$ & $\begin{array}{l}\text { Compatible with wide range of materials, } \\
\text { surface chemistries and morphologies. }\end{array}$ \\
\hline Direct laser fabrication & $\begin{array}{l}\text { Nd:YAG laser produces high intensity, } \\
\text { finely crystallised parts with lower } \\
\text { plasticity and oriented solidification structure. }\end{array}$ \\
\hline
\end{tabular}

concluded that LC is better than low-pressure cold spraying in terms of obtaining good mechanical and anticorrosive properties [42]. The comparison made by Ref. [42] is reproduced in Table 7. Recently, 3D printed tablets have been produced through SLS, which reflects SLS's application in pharmaceutical sciences [135].

Aboulkhair et al. [41] found that magnesium ( $\mathrm{Mg})$ is highly susceptible to evaporation or scatter during laser processing. Therefore, they used less $\mathrm{Mg}$ content in the parts than the previous raw virgin powder. Analysis of the debris showed an excess Mg content, thus confirming the claim that susceptibility does not affect melting and solidification behavior. However, the effect of the resulting change in composition on the mechanical properties and precipitate formation requires further investigation [41]. Shuai et al. [136] discovered that despite the good biodegradability and biocompatibility of zinc ( $\mathrm{Zn})$, it does not have the hardness and strength required for bone implants. However, in their work, silver (Ag)-Zn alloy prepared by SLM resulted in a $100 \%$ increase in compressive strength and a $116 \%$ increase in hardness. The alloy underwent the following changes: Constitutional undercooling in front of the advancing solid/liquid interface during solidification when $\mathrm{Ag}$ dissolved in $\mathrm{Zn}$ and $\mathrm{AgZn}_{3}$ phase formation occurred beyond the solid solubility. Each change was followed by further refinements to the grains. However, excessive Ag content coarsened the grains and reduced the mechanical properties. This result indicated that grain size and intermetallic phase are key factors that affect the biodegradation of $\mathrm{Mg}$ alloys.

Shuai et al. [137] reported that SLM can be used to achieve different grain sizes and intermetallic phase volume fractions by introducing $\mathrm{Al}$ into $\mathrm{Mg}-\mathrm{Zn}$ alloy. $\mathrm{An}$ 
Table 7 Properties' comparison for the laser cladded and cold sprayed thick copper coatings

\begin{tabular}{lcc}
\hline Parameters & Laser cladding & Cold spray coating \\
\hline Thickness range & $1-3 \mathrm{~mm}$ & $3 \mathrm{~mm}$ \\
Adhesion strength & $48 \mathrm{MPa}$ & $\begin{array}{c}\text { Very less (coating detached from } \\
\text { substrate during handling) }\end{array}$ \\
Porosity & $>2 \%$ & $<1 \%$ \\
Tensile strength & $180 \mathrm{MPa}$ & $170 \mathrm{MPa}$ \\
Elongation & $11 \%$ & $7 \%$ \\
Electrical conductivity & Not measured & $53 \mathrm{MSU}$ \\
Thermal conductivity & $140 \mathrm{~W} /(\mathrm{m} \cdot \mathrm{K})$ & $>200 \mathrm{~W} /(\mathrm{m} \cdot \mathrm{K})$ \\
Density & $7.65 \mathrm{~g} / \mathrm{mL}^{3}(89 \%)$ & $7.40 \mathrm{~g} / \mathrm{mL}^{3}(86 \%)$ \\
Corrosion rate & $17.77 \times 10^{-3} \mathrm{mpy}$ & $342.7 \times 10^{-3} \mathrm{mpy}$ \\
\hline
\end{tabular}

Note: MSU: miso-Siemens; $1 \mathrm{mpy}=0.0254 \mathrm{~mm} / \mathrm{a}$

increasing $\mathrm{Al}$ content results in grain refinement and an increase in intermetallic phase volume fraction. Grain refinement is the major factor that affects degradation when $\mathrm{Al}$ is less than $3 \mathrm{wt} \%$. This finding is attributed to the passivation of alloy due to the grain boundaries created by a finer grain. Further refinement to grain size and a further increase in degradation behavior were achieved in the study with further concentrations of Al. Large intermetallic phase volume fractions accelerated degradation by causing severe galvanic corrosion. This work helped in balancing the above factors and their effects on degradation and thus facilitated the development of bio-implant materials.

Laser-melted Mg-3Zn- $x$ Dy $(x=0,1,3,5 \mathrm{wt} \%)$ alloys have also been considered candidates for bio-implant applications. $\alpha-\mathrm{Mg}, \mathrm{MgZn}_{2}$, and $\mathrm{Mg}-\mathrm{Zn}-\mathrm{Dy}$ phases have been found to be distributed in the alloys with Dy. Alloys with Dy have significantly refined grain sizes [138]. Hardness monotonously increases with a decrease in grain size and an increase in second phase content. A low average hydrogen evolution rate indicates highly reduced degradation rates in the immersion testing degradation characteristic analysis. The rate of mechanical integrity loss during degradation indicates the alloys' potential in bio-implant applications. A refined grain size, homogenous microstructure, and second phase content produced during SLM contribute to decreased degradation rates [138].

\section{Discussion and findings}

The extensive literature reveals that researchers have widely applied or developed RM processes for different materials to manufacture functional high-quality parts that are superior or equivalent to those obtained from $\mathrm{CNC}$ machining. The processes that were applied were directly based on the $\mathrm{AM} / \mathrm{RM}$ process. The purpose of developing new $\mathrm{AM} / \mathrm{RM}$ processes is to alleviate the human intervention involved in $\mathrm{CNC}$ machining, enhance the properties of parts, and optimize the cost and time of the processes. Various properties, such as elongation, hardness, density, porosity, deformation, temperature distribution, strength, elastic modulus, and shrinkage ratio, were studied. The alloys considered for manufacturing were Ti-based alloy of Ti-6Al-4V, stainless steel powder of grade $316 \mathrm{~L}$, and Ni-based alloy Inconel. Researchers focused on EBM for manufacturing Ti-based alloy products, SLM for stainless steel-based products, DLMD for Ni-based alloy products, and investment casting for Al-based alloy products. Ti-based alloy was mainly used to fabricate cylindrical components (bones) and in aeronautics. Ni-based alloy was used to produce bone, dies, and punch, and stainless steel was adopted to produce geometry products, tubes, and thin walls. Al-based alloy was utilized to fabricate microchips and propellers. $\mathrm{Pb}$-based alloy was adopted to create printed circuits and other micro-components. To the best of the authors' knowledge, very few researchers have paid attention to the manufacture of iron, molybdenum, and $\mathrm{Pb}$-based alloy products. Therefore, the focus should be on applying the developed processes for these alloys and testing their performance. The alloys were selected based on the requirement of the properties of a specific product. Uncertainty exists in the selection of an optimal alloy for fabrication purposes due to the high degree of similarity in the properties of the alloys. Very few have performed scanning tests to select the optimal end material to be used for the fabrication of products [139]. This procedure may be time consuming and involves a waste of resources. A serious limitation is that the selection of the RM/AM process is to be done in consideration of the geometry, quality, and quantity of the product required. Thus, unlike those in traditional machining methods, the materials and process are interdependent. Moreover, the material used in powder form possesses constraints, such as melting point of the metal, cooling behavior of the metal, and material magnetism. The unusual cooling rate of the material could introduce undesirable metal properties to the prototyped part. For processes based on deposition phenomenon (arc, laser, and beam), the size and shape of the powder particles 
are of main concern because spherical powder particles are required to acquire a uniform flow for powder feeding. A powder with a particle size distribution within the acceptable range required for specific application needs to be selected. An extremely small powder particle could be carried away by carriage gas during deposition, and an extremely large particle may not melt properly. An attempt was also made to develop new materials by electroforming, intermettalic coating, and hybridization of two materials to help enhance the properties of the metallic product. However, the main focus of researchers was developing new processes, such as SLS-SLM, PLDM, arc HLM, HLM, RP-integrated investment casting, and GMAW, via the hybridization of two processes $[32,56,77,86,111$, $124,140]$. Although these developments have revolutionized the era of RP into RM/AM, the processes developed can be applied to only a particular type of an alloy and consume much time. Moreover, the properties of the product obtained still do not fully match those obtained from $\mathrm{CNC}$ machining. Very few have studied the influence of process parameters on the properties of a product to optimize the given process in terms of time, cost, and properties of a product $[132,134]$. The experiments were conducted based on parameter settings recommended by manufacturers, which can certainly induce uncertainty in the final outcome of the process depending on the expert knowledge of the manufacturers. Only mathematical models based on the FEM and regression analysis were developed to predict the process performance $[58,72,141]$. These methods are not commendable because of their inability to generalize or extrapolate the given data or information. Therefore, the focus of researchers should also be on the simultaneous optimization of these processes by building mathematical models using advanced machine learning methods [142-147]. Doing so will help analyze the process and can provide feedback to adjust the process according to economic conditions.

Although many RM/AM processes and new materials are being developed, very few researchers have compared the performance of these processes or materials to help the industry select the appropriate processes or materials for the fabrication of metallic products $[49,53,71,148]$. This is a remarkable industrial application that requires considerable attention. Thus, a guide that can assist researchers and industry people in selecting the given material and process based on their requirement of the final end-use product needs to be developed.

Metal printing using 3D printers can produce metal prototypes of any shape and complexity. However, the final product of a 3D printer generally possesses low quality when compared with the products of traditional manufacturing processes, such as welding, casting, and machining. Therefore, topology design optimization is vital in minimizing material usage and producing high-quality products. To this extent, some work on design optimization in consideration of uncertainties in systems $[149,150]$ can be performed to produce optimal product designs. Moreover, the role of robotics in rapid manufacturing for printing large complex aerospace parts could be useful for revolutionizing the present manufacturing industry [151,152]. Therefore, future trends should incorporate multiple aspects, not only the development of new alloys, but also finite element analysis, topology design optimization, and robotics [153] to pave the way for the advancement of the automation of AM of metallic products.

\section{- Latest trends in laser-aided AM}

Huang et al. [147] fabricated a hybrid Ni/Ti-6Al-4V structural component via an innovative hybrid AM process that combines two effective AM techniques: SLM and cold spraying (CS). A Eulerian model was used to study the deposition behavior of Ni on Ti-6Al-4V. The influence of vacuum heat treatment on the interfacial microstructure and adhesion strength of the hybrid structural component was examined. Similarly, Murr et al. [154] investigated hybrid AM by combining EBM and SLS and achieved good results. Yin et al. [155] used a new hybrid AM technology for fabricating functionally graded materials. The new process is a combination of two existing AM processes: SLM and CS. Bordeenithikasem et al. [156] produced metallic glass using laser foil printing (annealed it by laser spike annealing method) [157] and achieved better properties than the properties of bulk metallic glass produced by other conventional methods. Recently, researchers have begun the optimization of AM by scheduling a single machine using the genetic algorithm for saving time and cost [158]. A complete path of movement of manufacturing techniques from conventional to advanced can be observed from the above discussion and is presented in Fig. 3.

\section{Future scope}

The discussions reveal that improved results/properties can be obtained with LAAM in combination with another AM process, such as EBM, CS, and thermal spraying. LAAM can also be used for manufacturing various standalone metallic parts/components with improved mechanical properties compared with the parts produced by other conventional methods. The cost and time devoted to manufacturing parts can be reduced by optimizing machine scheduling using genetic algorithms. However, laser-based AM can be improved further by introducing machine learning, genetic algorithms, artificial intelligent, and other computer-based automatic systems by in situ detection and reduction of the manufacturing defects occurring during the process and by optimizing the process. The parts made from materials, such as ceramics and glass, which are difficult to machine and manufacture, may be manufactured by LAAM and any hybrid manufacturing method. 


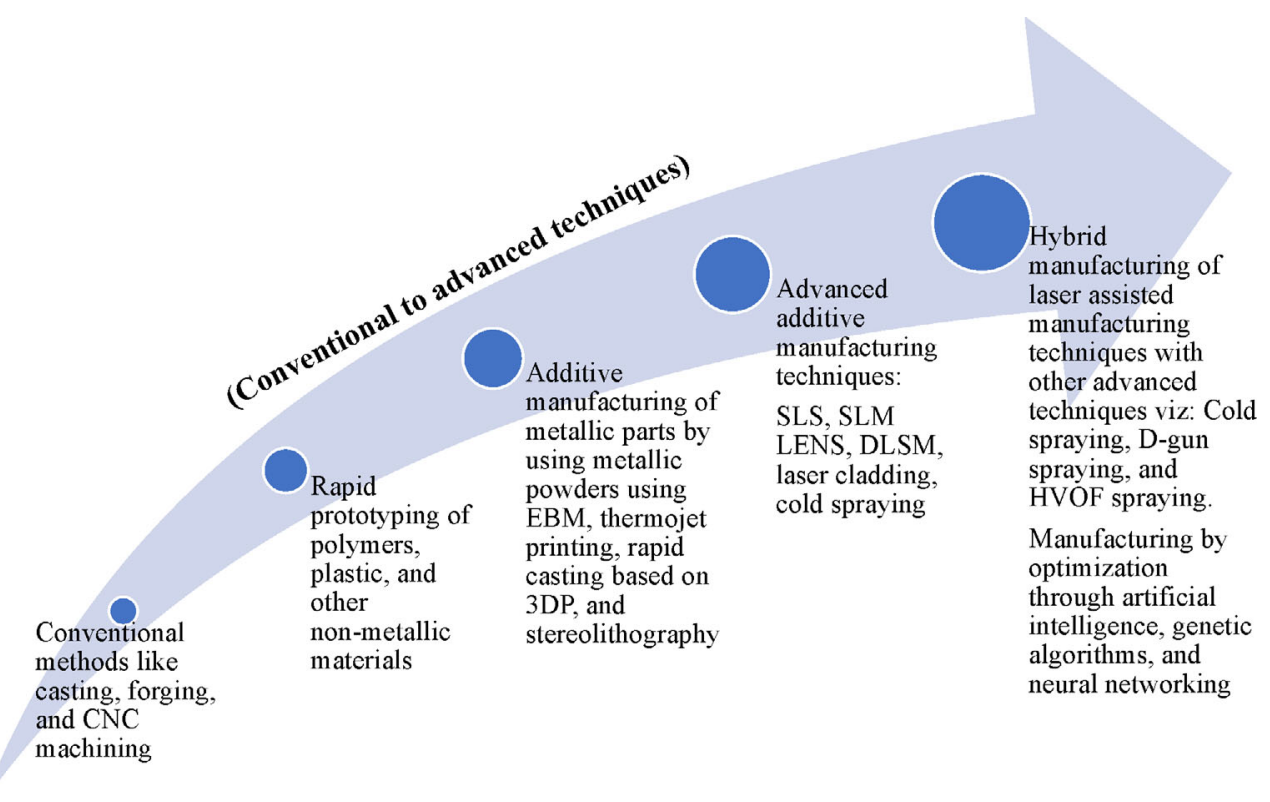

Fig. 3 Path of movement of manufacturing techniques from conventional to advanced. HVOF: High velocity oxy-fuel

\begin{abstract}
Acknowledgements This work was supported by Shantou University Scientific Research Fund (Grant No. NTF 16002) and Guangdong Sailing Plan for scientists. The authors also acknowledge the support of Guangdong University Youth Innovation Talent Project (Grant No. 2016KQNCX053) through the Department of Education of Guangdong Province. This study was also supported by a grant from an international science and technology collaboration project between China and Israel (Grant No. 2017A050501061) founded by Guangdong Science and Technology Department.
\end{abstract}

Open Access This article is distributed under the terms of the Creative Commons Attribution 4.0 International License (http://creativecommons.org/ licenses/by/4.0/), which permits unrestricted use, distribution, and reproduction in any medium, provided the appropriate credit is given to the original author(s) and the source, and a link is provided to the Creative Commons license, indicating if changes were made.

\section{References}

1. Forno A J D, Pereira F A, Forcellini F A, et al. Value stream mapping: A study about the problems and challenges found in the literature from the past 15 years about application of lean tools. International Journal of Advanced Manufacturing Technology, 2014, 72(5-8): 779-790

2. Govindan K, Rajendran S, Sarkis J, et al. Multi criteria decision making approaches for green supplier evaluation and selection: A literature review. Journal of Cleaner Production, 2015, 98: 66-83

3. Yan X, Gu P. A review of rapid prototyping technologies and systems. Computer Aided Design, 1996, 28(4): 307-318

4. Dickens P. Research developments in rapid prototyping. Proceedings of the Institution of Mechanical Engineers. Part B, Journal of Engineering Manufacture, 1995, 209(4): 261-266

5. Simchi A, Petzoldt F, Pohl H. On the development of direct metal laser sintering for rapid tooling. Journal of Materials Processing
Technology, 2003, 141(3): 319-328

6. Wohlers $\mathrm{T}$ T. Worldwide development \& trends in rapid prototyping and manufacturing. In: Proceedings of the $1 \mathrm{st}$ International Conference Rapid Prototyping and Manufacturing. Beijing, 1998

7. Xie J, Fox P, O'neill W, et al. Effect of direct laser re-melting processing parameters and scanning strategies on the densification of tool steels. Journal of Materials Processing Technology, 2005, 170(3): 516-523

8. Zhang K, Liu W, Shang X. Research on the processing experiments of laser metal deposition shaping. Optics \& Laser Technology, 2007, 39(3): 549-557

9. Moghaddam N S, Jahadakbar A, Amerinatanzi A. Recent advances in laser-based additive manufacturing. In: Bian L, Shamsaei N, Usher J, eds. Laser-Based Additive Manufacturing of Metal Parts: Modeling, Optimization, and Control of Mechanical Properties. Boca Raton: CRC Press, 2017, 1-24

10. Unocic R, Dupont J. Composition control in the direct laserdeposition process. Metallurgical and Materials Transactions. B, Process Metallurgy and Materials Processing Science, 2003, 34(4): 439-445

11. Wee L, Li L. Multiple-layer laser direct writing metal deposition in electrolyte solution. Applied Surface Science, 2005, 247(1-4): 285-293

12. Hua G, Zhao J, Zhang J, et al. Rapid manufacturing of metal parts. Journal of Southeast University, 2002, 18: 123-127

13. Wohlert M, Bourell D L, Das S, et al. Applications of powder densification maps to direct metal SLS/HIP processing. In: Proceedings of Solid Freeform Fabrication Symposium. 2000, $150-158$

14. Das S, Beama J J, Wohlert M, et al. Direct laser freeform fabrication of high performance metal components. Rapid Prototyping Journal, 1998, 4(3): 112-117 
15. Choi D S, Lee S, Shin B, et al. Development of a direct metal freeform fabrication technique using $\mathrm{CO}_{2}$ laser welding and milling technology. Journal of Materials Processing Technology, 2001, 113(1-3): 273-279

16. Pan H, Zhou T. Generation and optimization of slice profile data in rapid prototyping and manufacturing. Journal of Materials Processing Technology, 2007, 187-188: 623-626

17. Huang S H, Liu P, Mokasdar A, et al. Additive manufacturing and its societal impact: A literature review. International Journal of Advanced Manufacturing Technology, 2013, 4: 1-13

18. Chen L, He Y, Yang Y, et al. The research status and development trend of additive manufacturing technology. International Journal of Advanced Manufacturing Technology, 2017, 89(9-12): 36513660

19. Mohan N, Senthil P, Vinodh S, et al. A review on composite materials and process parameters optimisation for the fused deposition modelling process. Virtual and Physical Prototyping, 2017, 12(1): 47-59

20. Greul M, Pintat T, Greulich M. Rapid prototyping of functional metallic parts. Computers in Industry, 1995, 28(1): 23-28

21. Bártolo P J D S, Batista F D C. Virtual Modelling and Rapid Manufacturing. Abingdon: Taylor \& Francis Group, 2006

22. Skardal A, Atala A. Biomaterials for integration with 3-D bioprinting. Annals of Biomedical Engineering, 2015, 43(3): 730-746

23. Boparai K S, Singh R, Singh H. Development of rapid tooling using fused deposition modeling: A review. Rapid Prototyping Journal, 2016, 22(2): 281-299

24. Patil S N, Mulay A V, Ahuja B B. Development of experimental setup of metal rapid prototyping machine using selective laser sintering technique. Journal of the Institution of Engineers (India): Series C, 2018, 99(2): 159-167

25. Sapate K D, Apte T U. Metal fabrication by additive manufacturing. International Journal of Current Engineering and Technology, 2017, 7(1): 9-14

26. Blackwell P, Wisbey A. Laser-aided manufacturing technologies; their application to the near-net shape forming of a high-strength titanium alloy. Journal of Materials Processing Technology, 2005, 170(1-2): 268-276

27. Horii T, Kirihara S, Miyamoto Y. Freeform fabrication of Ti-Al alloys by 3D micro-welding. Intermetallics, 2008, 16(11-12): $1245-1249$

28. Spencer J, Dickens P, Wykes C. Rapid prototyping of metal parts by three-dimensional welding. Proceedings of the Institution of Mechanical Engineers. Part B, Journal of Engineering Manufacture, 1998, 212(3): 175-182

29. Klingbeil N, Beuth J, Chin R, et al. Residual stress-induced warping in direct metal solid freeform fabrication. International Journal of Mechanical Sciences, 2002, 44(1): 57-77

30. Mazumder J, Dutta D, Kikuchi N, et al. Closed loop direct metal deposition: Art to part. Optics and Lasers in Engineering, 2000, 34 (4-6): 397-414

31. Designation A S T M. F2792-12a. Standard Terminology for Additive Manufacturing Technologies. ISO 10303. West Conshohocken: ASTM International, 2012

32. Karunakaran K, Suryakumar S, Pushpa V, et al. Retrofitment of a
CNC machine for hybrid layered manufacturing. International Journal of Advanced Manufacturing Technology, 2009, 45(7-8): 690-703

33. Kruth J P, Froyen L, Van Vaerenbergh J, et al. Selective laser melting of iron-based powder. Journal of Materials Processing Technology, 2004, 149(1-3): 616-622

34. Levy G N, Schindel R, Kruth J P. Rapid manufacturing and rapid tooling with layer manufacturing (LM) technologies, state of the art and future perspectives. CIRP Annals-Manufacturing Technology, 2003, 52(2): 589-609

35. Yan J, Battiato I, Fadel G. Design of injection nozzle in direct metal deposition (DMD) manufacturing of thin-walled structures based on 3D models. International Journal of Advanced Manufacturing Technology, 2016, 5: 1-12

36. Laeng J, Stewart J, Liou F W. Laser metal forming processes for rapid prototyping - A review. International Journal of Production Research, 2000, 38(16): 3973-3996

37. Bernard A, Taillandier G, Karunakaran K. Evolutions of rapid product development with rapid manufacturing: Concepts and applications. International Journal of Rapid Manufacturing, 2009, 1(1): 3-18

38. Ferreira J, Bártolo P J D S, Alves N, et al. Rapid metal casting-A review of present status. Virtual and Rapid Manufacturing: Advanced Research in Virtual and Rapid Prototyping, 2007, 469: $1-7$

39. Song L, Mazumder J. US Patent, 9044827, 2015-06-02

40. Zhang J, Liou F, Seufzer W, et al. A coupled finite element cellular automaton model to predict thermal history and grain morphology of Ti-6Al-4V during direct metal deposition (DMD). Additive Manufacturing, 2016, 11: 32-39

41. Aboulkhair N T, Everitt N M, Ashcroft I, et al. Reducing porosity in AlSi10Mg parts processed by selective laser melting. Additive Manufacturing, 2014, 1-4: 77-86

42. Singh S, Kumar M, Sodhi G P S, et al. Development of thick copper claddings on SS316L steel for in-vessel components of fusion reactors and copper-cast iron canisters. Fusion Engineering and Design, 2018, 128: 126-137

43. Islam M, Purtonen $\mathrm{T}$, Piili $\mathrm{H}$, et al. Temperature profile and imaging analysis of laser additive manufacturing of stainless steel. Physics Procedia, 2013, 41: 835-842

44. Khan S Z, Masood S H, Cottam R. Mechanical properties of a novel plymetal manufactured by laser-assisted direct metal deposition. International Journal of Advanced Manufacturing Technology, 2017, 91(5-8): 1839-1849

45. Yakout M, Cadamuro A, Elbestawi M A, et al. The selection of process parameters in additive manufacturing for aerospace alloys. International Journal of Advanced Manufacturing Technology, 2017, 5: 1-18

46. Zhang Y, Xiu P, Jia Z, et al. Effect of vanadium released from micro-arc oxidized porous Ti6Al4V on biocompatibility in orthopedic applications. Colloids and Surfaces. B, Biointerfaces, 2018, 169: 366-374

47. Srivastava A K, Pavel R. Grinding investigations of Ti-6Al-4V parts produced using direct metal laser sintering technology. International Journal of Mechatronics and Manufacturing Systems, 2015, 8(5-6): 223-242 
48. Baufeld B, Van Der Biest O, Dillien S. Texture and crystal orientation in Ti-6Al-4V builds fabricated by shaped metal deposition. Metallurgical and Materials Transactions. A, Physical Metallurgy and Materials Science, 2010, 41(8): 1917-1927

49. Miranda R, Lopes G, Quintino L, et al. Rapid prototyping with high power fiber lasers. Materials \& Design, 2008, 29(10): 20722075

50. Wang T, Zhu Y Y, Zhang S Q, et al. Grain morphology evolution behavior of titanium alloy components during laser melting deposition additive manufacturing. Journal of Alloys and Compounds, 2015, 632: 505-513

51. Liu Q, Wang Y, Zheng H, et al. TC17 titanium alloy laser melting deposition repair process and properties. Optics \& Laser Technology, 2016, 82: 1-9

52. Gibson I, Rosen D, Stucker B. Additive Manufacturing Technologies: 3D Printing, Rapid Prototyping, and Direct Digital Manufacturing. New York: Springer, 2015

53. Lopes G, Williams S, Miranda R, et al. Additive manufacturing of Ti-6Al-4V based components with high power fiber lasers. In: Bártolo P J D S, Jorge M A, Batista F D C, et al., ed. Virtual and Rapid Manufacturing: Advanced Research in Virtual and Rapid Prototyping. Boca Raton: CRC Press, 2007, 369-374

54. Biffi C A, Demir A G, Coduri M, et al. Laves phases in selective laser melted TiCr1.78 alloys for hydrogen storage. Materials Letters, 2018, 226: 71-74

55. Rolchigo M R, LeSar R. Modeling of binary alloy solidification under conditions representative of additive manufacturing. Computational Materials Science, 2018, 150: 535-545

56. Mizuta N, Matsuura K, Kirihara S, et al. Titanium aluminide coating on titanium surface using three-dimensional microwelder. Materials Science and Engineering A, 2008, 492(1-2): 199-204

57. Katou M, Oh J, Miyamoto Y, et al. Freeform fabrication of titanium metal and intermetallic alloys by three-dimensional micro welding. Materials \& Design, 2007, 28(7): 2093-2098

58. Rahmati S, Farahmand F, Abbaszadeh F. Application of rapid prototyping for development of custom-made orthopedics prostheses: An investigative study. International Journal of Advanced Design and Manufacturing Technology, 2011, 3: 11-16

59. Sing S L, Yeong W Y, Wiria F E. Selective laser melting of titanium alloy with 50 wt\% tantalum: Microstructure and mechanical properties. Journal of Alloys and Compounds, 2016, 660: 461-470

60. Wu W, Tor S B, Leong K F, et al. State of the art review on selective laser melting of stainless steel for future applications in the marine Industry. In: Proceedings of the 2nd International Conference on Progress in Additive Manufacturing (Pro-AM 2016). Singapore, 2016, 475-481

61. Everton S K, Hirsch M, Stravroulakis P, et al. Review of in-situ process monitoring and in-situ metrology for metal additive manufacturing. Materials \& Design, 2016, 95: 431-445

62. Fayazfar H, Salarian M, Rogalsky A, et al. A critical review of powder-based additive manufacturing of ferrous alloys: Process parameters, microstructure and mechanical properties. Materials \& Design, 2018, 144: 98-128

63. Charmeux J, Minev R, Dimov S, et al. Benchmarking of three processes for producing castings incorporating micro/mesoscale features with a high aspect ratio. Proceedings of the Institution of Mechanical Engineers. Part B, Journal of Engineering Manufacture, 2007, 221(4): 577-588

64. Bibb R, Eggbeer D, Evans P, et al. Rapid manufacture of customfitting surgical guides. Rapid Prototyping Journal, 2009, 15(5): 346-354

65. Aiyiti W, Zhao W, Lu B, et al. Investigation of the overlapping parameters of MPAW-based rapid prototyping. Rapid Prototyping Journal, 2006, 12(3): 165-172

66. España F A, Balla V K, Bandyopadhyay A. Laser surface modification of AISI 410 stainless steel with brass for enhanced thermal properties. Surface and Coatings Technology, 2010, 204 (15): 2510-2517

67. Joo S, Baldwin D F. Advanced package prototyping using nanoparticle silver printed interconnects. IEEE Transactions on Electronics Packaging Manufacturing, 2010, 33(2): 129-134

68. Qi H, Yan Y, Lin F, et al. Scanning method of filling lines in electron beam selective melting. Proceedings of the Institution of Mechanical Engineers. Part B, Journal of Engineering Manufacture, 2007, 221(12): 1685-1694

69. Deng Q L, Xie A N, Ge Z J, et al. Experimental researches on rapid forming full compacted metal parts by selective laser melting. Materials Science Forum, 2006, 532-533: 428-431

70. Fu G, Tor S, Loh $\mathrm{N}$, et al. A micro powder injection molding apparatus for high aspect ratio metal micro-structure production. Journal of Micromechanics and Microengineering, 2007, 17(9): 1803-1809

71. Ghany K A, Moustafa S F. Comparison between the products of four RPM systems for metals. Rapid Prototyping Journal, 2006, 12 (2): 86-94

72. Mughal M, Fawad H, Mufti R. Three-dimensional finite-element modelling of deformation in weld-based rapid prototyping. Proceedings of the Institution of Mechanical Engineers. Part C, Journal of Mechanical Engineering Science, 2006, 220(6): 875885

73. Casavola C, Campanelli S, Pappalettere C. Preliminary investigation on distribution of residual stress generated by the selective laser melting process. Journal of Strain Analysis for Engineering Design, 2009, 44(1): 93-104

74. Costa L, Rajput D, Lansford K, et al. The tower nozzle solid freeform fabrication technique. Rapid Prototyping Journal, 2010, 16(4): 295-301

75. Yan C, Hao L, Hussein A, et al. Advanced lightweight 316L stainless steel cellular lattice structures fabricated via selective laser melting. Materials \& Design, 2014, 55: 533-541

76. Khairallah S A, Anderson A. Mesoscopic simulation model of selective laser melting of stainless steel powder. Journal of Materials Processing Technology, 2014, 214(11): 2627-2636

77. Cherry J A, Davies H M, Mehmood S, et al. Investigation into the effect of process parameters on microstructural and physical properties of 316L stainless steel parts by selective laser melting. International Journal of Advanced Manufacturing Technology, 2015, 76(5-8): 869-879

78. Trevisan F, Calignano F, Lorusso M, et al. On the selective laser melting (SLM) of the AlSi10Mg alloy: Process, microstructure, and mechanical properties. Materials (Basel), 2017, 10(1): 76 
79. Tucho W H, Lysne V, Austbø H, et al. Investigation of effects of process parameters on microstructure and hardness of SLM manufactured SS316L. Journal of Alloys and Compounds, 2018, 740: $910-925$

80. Bartolomeu F, Buciumeanu M, Pinto E, et al. 316L stainless steel mechanical and tribological behavior-A comparison between selective laser melting, hot pressing and conventional casting. Additive Manufacturing, 2017, 16: 81-89

81. Kong D, Ni X, Dong C, et al. Heat treatment effect on the microstructure and corrosion behavior of $316 \mathrm{~L}$ stainless steel fabricated by selective laser melting for proton exchange membrane fuel cells. Electrochimica Acta, 2018, 276: 293-303

82. Sudhakar K V, Rawn P, Coguill R, et al. Mechanical properties and microstructure evaluation of biomaterial grade $316 \mathrm{~L}$ stainless steel produced by additive manufacturing. European Journal of Advances in Engineering and Technology, 2018, 5(2): 106-112

83. Shamsaei N, Yadollahi A, Bian L, et al. An overview of direct laser deposition for additive manufacturing; Part II: Mechanical behavior, process parameter optimization and control. Additive Manufacturing, 2015, 8: 12-35

84. Segerstark A, Andersson J, Svensson L E. Evaluation of the effect of process parameters on microstructural characteristics in laser metal deposition of alloy 718. Journal of Optics and Laser Technology, 2015, 93(8): 1483-1489

85. Lewandowski J J, Seifi M. Metal additive manufacturing: A review of mechanical properties. Annual Review of Materials Research, 2016, 46(1): 151-186

86. Qian Y P, Huang J H, Zhang H O, et al. Direct rapid hightemperature alloy prototyping by hybrid plasma-laser technology. Journal of Materials Processing Technology, 2008, 208(1-3): 99104

87. Dinda G, Dasgupta A, Mazumder J. Laser aided direct metal deposition of Inconel 625 superalloy: Microstructural evolution and thermal stability. Materials Science and Engineering A, 2009, 509(1-2): 98-104

88. Horii T, Kirihara S, Miyamoto Y. Freeform fabrication of superalloy objects by 3D micro welding. Materials \& Design, 2009, 30(4): 1093-1097

89. Minagawa K, Kakisawa H, Takamori S, et al. Application of 3-dimensional powder laminating fabrication to metallic components. Materials Science Forum, 2007, 539-543

90. Osakada K, Shiomi M. Flexible manufacturing of metallic products by selective laser melting of powder. International Journal of Machine Tools and Manufacture, 2006, 46(11): 11881193

91. Angelastro A, Campanelli S L, Ludovico A D. Characterization of Colmonoy 227-F samples obtained by direct laser metal deposition. Advanced Materials Research, 2010, 83: 842-849

92. Gordon L, Bouwhuis B, Suralvo M, et al. Micro-truss nanocrystalline Ni hybrids. Acta Materialia, 2009, 57(3): 932-939

93. Dressler M, Röllig M, Schmidt M, et al. Temperature distribution in powder beds during 3D printing. Rapid Prototyping Journal, 2010, 16(5): 328-336

94. Hanumaiah N, Ravi B. Rapid tooling form accuracy estimation using region elimination adaptive search based sampling technique. Rapid Prototyping Journal, 2007, 13(3): 182-190
95. Chen B, Mazumder J. Role of process parameters during additive manufacturing by direct metal deposition of Inconel 718. Rapid Prototyping Journal, 2017, 23(5): 919-929

96. Singh A, Ramakrishnan A, Baker D, et al. Laser metal deposition of nickel coated Al 7050 alloy. Journal of Alloys and Compounds, 2017, 719: 151-158

97. Bi G, Gasser A. Restoration of nickel-base turbine blade knifeedges with controlled laser aided additive manufacturing. Physics Procedia, 2011, 12: 402-409

98. Kanagarajah P, Brenne F, Niendorf T, et al. Inconel 939 processed by selective laser melting: Effect of microstructure and temperature on the mechanical properties under static and cyclic loading. Materials Science and Engineering A, 2013, 588: 188-195

99. Nie P, Ojo O A, Li Z. Numerical modeling of microstructure evolution during laser additive manufacturing of a nickel-based superalloy. Acta Materialia, 2014, 77: 85-95

100. Sateesh N H, Kumar G C M, Krishna P. Influence of Ni-P coated $\mathrm{SiC}$ and laser scan speed on the microstructure and mechanical properties of IN625 metal matrix composites. Lasers in Manufacturing and Materials Processing, 2015, 2(4): 187-198

101. Marattukalam J J, Singh A K, Datta S, et al. Microstructure and corrosion behavior of laser processed NiTi alloy. Materials Science and Engineering C, 2015, 57: 309-313

102. Hong C, Gu D, Dai D, et al. Laser additive manufacturing of ultrafine $\mathrm{TiC}$ particle reinforced Inconel 625 based composite parts: Tailored microstructures and enhanced performance. Materials Science and Engineering A, 2015, 635: 118-128

103. Klapper H S, Burns M, Molodtsov N, et al. Critical factors affecting the pitting corrosion resistance of additively manufactured Ni-based alloy in chloride containing environments. In: Proceedings of NACE-2017-9345. NACE International, 2017

104. Olakanmi E O T, Cochrane R F, Dalgarno K W. A review on selective laser sintering/melting (SLS/SLM) of aluminium alloy powders: Processing, microstructure, and properties. Progress in Materials Science, 2015, 74: 401-477

105. Bassoli E, Atzeni E. Direct metal rapid casting: Mechanical optimization and tolerance calculation. Rapid Prototyping Journal, 2009, 15(4): 238-243

106. Bassoli E, Gatto A, Iuliano L, et al. 3D printing technique applied to rapid casting. Rapid Prototyping Journal, 2007, 13(3): 148-155

107. Gill S S, Kaplas M. Comparative study of 3D printing technologies for rapid casting of aluminium alloy. Materials and Manufacturing Processes, 2009, 24(12): 1405-1411

108. Kang H J, Ahn S H. Fabrication and characterization of microparts by mechanical micromachining: Precision and cost estimation. Proceedings of the Institution of Mechanical Engineers. Part B, Journal of Engineering Manufacture, 2007, 221(2): 231-240

109. Pal D, Bhargava L, Ravi B, et al. Computer-aided reverse engineering for rapid replacement of parts. Defence Science Journal, DESSIDOC, 2006, 56(2): 225-238

110. Hsu C, Huang C, Tzou G. Using metallic resin and aluminum alloy molds to manufacture propellers with RP/RT technique. Rapid Prototyping Journal, 2008, 14(2): 102-107

111. Mondal B, Kundu S, Lohar A K, et al. Net-shape manufacturing of intricate components of $\mathrm{A} 356 / \mathrm{SiCp}$ composite through rapidprototyping-integrated investment casting. Materials Science and 
Engineering A, 2008, 498(1-2): 37-41

112. Yan C, Hao L, Hussein A, et al. Microstructure and mechanical properties of aluminium alloy cellular lattice structures manufactured by direct metal laser sintering. Materials Science and Engineering A, 2015, 628: 238-246

113. Prashanth K G, Shakur-Shahabi H, Attar H, et al. Production of high strength $\mathrm{Al}_{85} \mathrm{Nd}_{8} \mathrm{Ni}_{5} \mathrm{Co}_{2}$ alloy by selective laser melting. Additive Manufacturing, 2015, 6: 1-5

114. Kenel C, Schloth P, Van-Petegem S, et al. In situ synchrotron X-ray diffraction and small angle $\mathrm{X}$-ray scattering studies on rapidly heated and cooled Ti-Al and Al-Cu-Mg alloys using laser-based heating. JOM, 2016, 68(3): 978-984

115. Cabrini M, Lorenzi S, Pastore T, et al. Evaluation of corrosion resistance of Al-10Si-Mg alloy obtained by means of direct metal laser sintering. Journal of Materials Processing Technology, 2016, 231: $326-335$

116. Caiazzo F, Caggiano A. Laser direct metal deposition of $2024 \mathrm{Al}$ alloy: Trace geometry prediction via machine learning. Materials (Basel), 2018, 11(3): 444

117. Vora P, Martinez R, Hopkinson N, et al. Customised alloy blends for in-situ Al339 alloy formation using anchorless selective laser melting. Technologies, 2017, 5(2): 24

118. Kim M S, Chu W S, Kim Y M, et al. Direct metal printing of 3D electrical circuit using rapid prototyping. International Journal of Precision Engineering and Manufacturing, 2009, 10: 147-150

119. Vaezi M, Chianrabutra S, Mellor B, et al. Multiple material additive manufacturing - Part 1: A review. Virtual and Physical Prototyping, 2013, 8(1): 19-50

120. Gao S, Yao Y, Cui C. Vibrating breakup of jet for uniform metal droplets. Journal of Materials Science and Technology, 2007, 23: 135-138

121. Hsiao W K, Chun J H, Saka N. Effect of surface roughness on droplet bouncing in droplet-based manufacturing processes. CIRP Annals-Manufacturing Technology, 2006, 55(1): 209-212

122. Aghanajafi C, Daneshmand S. Integration of three-dimensional printing technology for wind-tunnel model fabrication. Journal of Aircraft, 2010, 47(6): 2130-2135

123. Baptista R, Silva M B, Saraiva C. Developments for rapid tooling application in sheet metal forming. Materials Science Forum, 2006, 514-516: 1516-1520

124. Karunakaran K, Suryakumar S, Pushpa V, et al. Low cost integration of additive and subtractive processes for hybrid layered manufacturing. Robotics and Computer-Integrated Manufacturing, 2010, 26(5): 490-499

125. Milovanovic J, Stojkovic M, Trajanovic M. Rapid tooling of tyre tread ring mould using direct metal laser sintering. Journal of Scientific and Industrial Research, 2009, 68(12): 1038-1042

126. Pacurar R, Balc N, Prem F. Research on how to improve the accuracy of the SLM metallic parts. AIP Conference Proceedings, 2011, 1353(1): 1385

127. Piqué A, Charipar N A, Kim H, et al. Applications of laser directwrite for embedding microelectronics. Proceedings Volume 6606, Advanced Laser Technologies, 2007, 66060R

128. Piqué A, Chrisey D B. Direct-Write Technologies for Rapid Prototyping Applications: Sensors, Electronics, and Integrated Power Sources. Salt Lake City: Academic Press, 2002
129. Monzón M, Hernández $\mathrm{P}$ M, Marrero M D, et al. New development in computer aided electroforming for rapid prototyping applications. In: Proceedings of ASME 2008 9th Biennial Conference on Engineering Systems Design and Analysis, Volume 1: Advanced Energy Systems; Advanced and Digital Manufacturing; Advanced Materials; Aerospace. Haifa: ASME, 2008, 179184

130. Meier H, Haberland C. Experimental studies on selective laser melting of metallic parts. Materials Science and Engineering, 2008, 39(9): 665-670

131. Berce $\mathrm{P}$, Chezan $\mathrm{H}, \mathrm{Balc} \mathrm{N}$. The application of rapid prototyping technologies for manufacturing the custom implants. In: Proceedings of ESAFORM Conference. Cluj-Napoca, 2005, 679-682

132. Chen J, Yang J, Zuo T. Micro fabrication with selective laser micro sintering. In: Proceedings of the 1st IEEE International Conference on Nano/Micro Engineered and Molecular Systems. Zhuhai: IEEE, 2006, 426-429

133. Chen G, Xiong Z, Lu Y, et al. Study on direct laser fabrication of Nd:YAG. SPIE Proceedings Vol. 6423: International Conference on Smart Materials and Nanotechnology in Engineering, 2007, 64234T

134. Dingal S, Pradhan T, Sundar J K S, et al. The application of Taguchi's method in the experimental investigation of the laser sintering process. International Journal of Advanced Manufacturing Technology, 2008, 38(9-10): 904-914

135. Fina F, Goyanes A, Madla C M, et al. 3D printing of drug-loaded gyroid lattices using selective laser sintering. International Journal of Pharmaceutics, 2018, 547(1-2): 44-52

136. Shuai C, He C, Feng P, et al. Biodegradation mechanisms of selective laser-melted $\mathrm{Mg}-x \mathrm{Al}-\mathrm{Zn}$ alloy: Grain size and intermetallic phase. Virtual and Physical Prototyping, 2018, 13(2): 5969

137. Shuai C, Xue L, Gao C, et al. Selective laser melting of Zn-Ag alloys for bone repair: Microstructure, mechanical properties and degradation behaviour. Virtual and Physical Prototyping, 2018, 13 (3): $146-154$

138. Long T, Zhang X, Huang Q, et al. Novel Mg-based alloys by selective laser melting for biomedical applications: Microstructure evolution, microhardness and in vitro degradation behaviour. Virtual and Physical Prototyping, 2018, 13(2): 71-81

139. Osakada K, Shiomi M. Flexible manufacturing of metallic products by selective laser melting of powder. International Journal of Machine Tools and Manufacture, 2006, 46(11): 11881193

140. Gordon L, Bouwhuis B, Suralvo M, et al. Micro-truss nanocrystalline Ni hybrids. Acta Materialia, 2009, 57(3): 932-939

141. Chatterjee A, Kumar S, Saha P, et al. An experimental design approach to selective laser sintering of low carbon steel. Journal of Materials Processing Technology, 2003, 136(1-3): 151-157

142. Garg A, Tai K. A hybrid genetic programming-Artificial neural network approach for modeling of vibratory finishing process. In: Proceedings of the International Conference on Information and Intelligent Computing. Singapore: IACSIT Press, 2011, 14-19

143. Hsu K, Gupta H V, Sorooshian S. Artificial neural network modeling of the rainfall-runoff process. Water Resources Research, 1995, 31(10): 2517-2530 
144. Hearst M A, Dumais S, Osman E, et al. Support vector machines. IEEE Intelligent Systems and their Applications, 1998, 13(4): 18 28

145. Bhattacharya B, Solomatine D. Neural networks and M5 model trees in modelling water level-discharge relationship. Neurocomputing, 2005, 63: 381-396

146. Deb K, Pratap A, Agarwal S, et al. A fast and elitist multiobjective genetic algorithm: NSGA-II. Evolutionary Computation. IEEE Transactions on Evolutionary Computation, 2002, 6(2): 182-197

147. Huang G, Min Z, Yang L, et al. Transpiration cooling for additive manufactured porous plates with partition walls. International Journal of Heat and Mass Transfer, 2018, 124: 1076-1087

148. Murr L, Esquivel E, Quinones S, et al. Microstructures and mechanical properties of electron beam-rapid manufactured Ti$6 \mathrm{Al}-4 \mathrm{~V}$ biomedical prototypes compared to wrought Ti-6Al-4V. Materials Characterization, 2009, 60(2): 96-105

149. Rajan A, Ooi M, Kuang Y C, et al. Efficient analytical moments for the robustness analysis in design optimisation. Journal of Engineering, 2016, 2016(11): 423-430

150. Rajan A, Ooi M, Kuang Y C, et al. Reliability-based design optimisation of technical systems: Analytical response surface moments method. Journal of Engineering, 2017, 2017(3): 36-49

151. Gómez A, Olmos V, Racero J, et al. Development based on reverse engineering to manufacture aircraft custom-made parts. International Journal of Mechatronics and Manufacturing Systems, 2017, 10(1): 40-58

152. Zhu Z, Xu W, Meng Z, et al. Optimal trajectory and placement of a
SCARA robot for natural yarns handling in the lattice distortion modification processing. International Journal of Mechatronics and Manufacturing Systems, 2015, 8(3-4): 85-101

153. Michas S, Matsas E, Vosniakos G C. Interactive programming of industrial robots for edge tracing using a virtual reality gaming environment. International Journal of Mechatronics and Manufacturing Systems, 2017, 10(3): 237-259

154. Murr L E, Gaytan S M, Ramirez D A, et al. Metal fabrication by additive manufacturing using laser and electron beam melting technologies. Journal of Materials Science and Technology, 2012, 28(1): 1-14

155. Yin S, Yan X, Chen C, et al. Hybrid additive manufacturing of AlTi6Al4V functionally graded materials with selective laser melting and cold spraying. Journal of Materials Processing Technology, 2018, 255: 650-655

156. Bordeenithikasem P, Shen Y, Tsai H L, et al. Enhanced mechanical properties of additively manufactured bulk metallic glasses produced through laser foil printing from continuous sheetmetal feedstock. Additive Manufacturing, 2018, 19: 95-103

157. Bordeenithikasem P, Stolpe M, Elsen A, et al. Glass forming ability, flexural strength, and wear properties of additively manufactured Zr-based bulk metallic glasses produced through laser powder bed fusion. Additive Manufacturing, 2018, 21: 312317

158. Fera M, Fruggiero F, Lambiase A, et al. A modified genetic algorithm for time and cost optimization of an additive manufacturing single-machine scheduling. International Journal of Industrial Engineering Computations, 2018, 9(4): 423-438 